\title{
An Exploratory Study on the Effect of Artificial Intelligence- Enabled Technology on Customer Experiences in the Banking Sector
}

\author{
Hatem El-Gohary, Qatar University, Doha, Qatar \\ (iD) https://orcid.org/0000-0001-6139-7054 \\ Aksaya Thayaseelan, Birmingham City University, UK \\ Simeon Babatunde, Birmingham City University, UK \\ Salma El-Gohary, Qatar University, Doha, Qatar
}

\begin{abstract}
This study investigates how artificial intelligence technology in the banking sector has affected consumers' overall experiences. It focuses on how consumer personal digital transformation has affected digital banking development and how this further affects consumer expectations and experience. It assesses how banks use artificially intelligent virtual agents such as chatbots to transform how consumers use their banking facilities. Lastly, this study investigates the scope of neobanks in the banking sector. The study found that digital transformations have led to an increase in consumer expectations from their banks. Whilst banks revolutionise their customer service offerings through virtual agents, customers are not engaging with these at an expected rate. Findings revealed that neobanks are not operating at their expected traction due to consumer knowledge gaps, occasioned by a lack of advertised information to customers from their banks.
\end{abstract}

\section{KEYWORDS}

Artificial Intelligence (AI), Chatbots, Customer Experience (CX), Customer Relationship Management (CRM), FinTech, Neobanks, Virtual Agent (VA)

\subsection{INTRODUCTION}

Incorporating ICT and technology with businesses in financial services has evolved, leading to complete revolutionising of the financial sector. However, there are various definitions and views of fintech, e.g. some scholars see the adoption of fintech as the use of technology in financial services, analysing data using automation, and translating output to improve a firm' purpose and delivery to its consumers (Vives, 2017; Schueffel, 2016). Technological developments, especially in banks, transformed the way consumers interact with banks as well as how they manage their finances.

DOI: 10.4018/JTA.20210101.oa1

This article published as an Open Access article distributed under the terms of the Creative Commons Attribution License (http://creativecommons.org/licenses/by/4.0/) which permits unrestricted use, distribution, and production in any medium, provided the author of the original work and original publication source are properly credited. 
This has led to fintech reshaping customers' expectations and setting new and high bars for user experience due to the rapid innovation of Artificial Intelligence (AI) within the sector (McWaters, 2017; Nicoletti et al., 2017; etc.).

The emergence and use of electronic applications and Artificial Intelligence (AI) have made a phenomenal impact on many existing firms and led to the creation of new types of businesses in the economy (Raghubansie, et al., 2015; and El-Gohary, 2011). AI is defined as a "grouping of methodologies backed by data and includes logic, networks, algorithms, embedded probability functions, and machine learning capabilities" (Binner et al., 2004, p.10). AI has enabled firms' formation with capabilities of being $100 \%$ digital, especially in sectors previously presumed impossible, and enabled a level of customer experience never thought of across various sectors (Hoyer et al., 2020; and Ameen et al., 2020). This is currently present in the financial industry, specifically in the banking sector, as Neobanks have become increasingly popular. The outstanding features of Neobanks are their reliance solely on cloud-based software, no physical presence for consumers to visit, adaptability, and they are becoming progressively more successful with the ease to use data to drive innovation (Kline, 2015; and Bradford, 2020).

Meanwhile, Customer Experience (CX) is continuously at the core of any firm, predominantly as a metric to measure satisfaction or otherwise. Consumers' expectations of the customer experience they receive have heightened and changed throughout time due to many reasons. Such experience is imperative in creating customer value (Eid and El-Gohary, 2015a; and 2015b). In the financial sector, the constant innovation and adoption of technology have been reasons for the rapid change in consumer expectations. This has put some pressure on firms to remain relevant and adapt such changes along with their customers. There are several definitions of CX, such as the one of Klaus and Maklan, 2013: "customer's cognitive and affective assessment of all direct and indirect encounters with the firm relating to their purchasing behaviour" (Klaus and Maklan, 2013). Moreover, Schwager and Meyer, 2007 view it as: "the internal and distinctive response customers have to their dealings with a company" (Schwager and Meyer, 2007). Both definitions allow for evaluating how or if AI has affected CX and customers' purchasing behaviour.

Due to the explosion of technology, there is a turbo effect on innovation (Shaw and Ivens, 2002, p. 17), thus forming the relationship between Artificial Intelligence and Customer Experience. This has led businesses in the banking sector to adopt AI-enabled technologies and create AI-powered CX Chatbots, also known as Virtual Agents (VA). Among several benefits, the use of machine learning in AI allows a firm to reduce its costs. Still, the improvements they make in CX are more impactful due to the bots availability of 24 hours, seven days a week, ability to learn, answer standard questions objectively, perhaps without any human error. Due to the natural language capabilities of a VA, there is a possibility of difficulty in confirming whether customers are interacting with a human or, in fact, a VA (Kannan and Bernoff, 2019).

In the later part of the past decade, the popularity of Neobanks increased and created particular traction with millennials and the underbanked. This is mainly due to their continuous approach to improving customer experience and has recently exacerbated by the recent COVID-19 pandemic that has led to banking solely from home (Kline, 2015; and Remolina, 2020). They commonly provide the same services that big banks offer, such as savings accounts, credit cards and paper checks. This allows the opportunity for consumers to hold their primary bank account with Neobanks rather than with a traditional banking firm (Kauflin, 2019; and Temelkov, 2020).

Therefore, this study has three main aims, which are:

- To explore the consumers' usage of digital banking and experiences,

- To examine how AI empowered technology in the banking sector and how it affected consumers' experience in banking overall, and;

- To investigate the scope and reaction to services provided by Neobanks. 


\subsection{LITERATURE REVIEW}

There is increasing evidence that recognises customer experience (CX) as necessary in any firm and establishing that it is a fundamental factor for success. From a firm's perspective, customer experience is essentially a way to manage what perception a consumer has of their business (Lemon and Verhoef, 2016). There are various definitions of Customer Experience, but this study adopted the definition provided by Shaw et al. (2010), which perceive customer experience as "an interaction between an organisation and a customer as perceived through a customers' conscious mind and intuitively measured against customer expectations across all moments of contact" (Shaw et al., 2010, p.3). Similarly, CX is defined by Buttle and Maklan (2015) as "the cognitive and affective outcome of the customer's exposure to, or interaction with, a company's people, processes, technologies, products, services and other outputs" (Buttle and Maklan, 2015). This review will adopt the aforementioned definition expressly.

Customer Experience is at the heart of every firm and a way to manage customer data and this experience is via a Customer Relationship Management (CRM) system. A definition of CRM in the banking sector is provided by Rajola (2013) as "a business strategy aiming to understand and to anticipate the needs of existing customers and seek new ones who might potentially be interested in product or services offered by a bank" (Rajola, 2013, p. 41). Therefore, to achieve this strategy, new processes are required to create systems based on integrated technologies to provide novel and steady sustenance to consumers' while using the bank different communication networks (Brown, 2000). Following this strategy, it is now apparent that more businesses in the banking industry are implementing such systems, especially with the use of Artificial Intelligence, such as digital banking services, Artificial Intelligence-powered Chatbots. Thereby allowing traditional banking services to be available 24 hours a day (MBAMA, 2018, p. 8).

The digital revolution has allowed the banking industry to transform the concept of digital banking by providing e-banking services to consumers. The revolution has allowed digital banking to become popular due to the simultaneous shift of customer expectations as a whole. Arslanian and Fischer (2019) explained that the shift in customer expectations, stating that standard technologies such as WhatsApp, Uber, Facebook have raised consumers expectations of digital services to be personalised, opportune, and especially on-demand. This has led consumers to conclude on viewing current offerings of financial services as outdated. They further stated that younger customers had expressed frustration with incumbent banks' level of experience (Arslanian and Fisher, 2019, p. 28). Due to this frustration, banks have either implemented new technologies into their business strategies or created entirely new digital banks, hence increasing the popularity of Neobanks and digital banking. Минарченко (2018) study explains that Neobanking is perhaps ideal for young people with straightforward banking needs (Минарченко (2018, p.1).

Studies have argued that customer services are enhanced by e-banking, which leads to retaining their customers (Joseph et al., 2005). Recent technologies have provided an enabling environment for Virtual Agents, interacting with consumers, providing an answer to questions, recommendations, and delivering advice without constraints and on-demand, essentially leading to the complete transformation of customer experience (Moysan and Zeitoun, 2019). Salvatore et al. (2016) conducted a study with several organisations across different industry sectors, providing insight into the connection between innovative technology and the customer experience journey. The study concluded that the interaction of two critical digital technology could result in an enriched customer experience: personalisation and interactivity. They concluded that personalisation encompassed provision of expertise and solution-using consumer's in-store behaviours and factors such as consumer's activities online noted favourites, and customers' demographics. This frequently results in an optimistic customer attitude toward the product brand, as the customer trusts the corporation prioritises and feel that the corporation value him/her (Liang et al., 2011). Klein (2003) observed from a study that the use of technology in areas such as augmented reality allows the enablement of the consumer to 
connect in real-time with a product expert in an immersive environment; thus, defining the concept of interactivity. The study further noted such experiences give buyers a notion of control as they interact about their desires and needs with brands.

The concept of digital banking is executed through various service channels, with telephones as one of the earliest e-banking services. Still, the popularity of the internet has enhanced computer banking's popularity, with mobile banking becoming more critical. These service channels provide the merits of suitability, ease, and concept of anywhere and anytime accessibility to the required service (Shaikh and Karjaluoto, 2015; and Sundarraj and Wu, 2005). Lipton et al. (2016) suggest that digital banks should provide a holistic and customisable experience from the retail point of view, be wholly digital and more. They observed that through the years, customers' expectations have evolved. Suppose traditional 'brick and mortar' banks are unable to innovate and digitally transform. In that case, they will no longer be able to satisfy the majority of their consumers and decrease revenue as a business. Meanwhile, Wewege (2017) study found that if retail banks pursued a full digital transformation, they could face improvements in earnings of more than 40 per cent over the next five years.

Over the past few years, there was a growing awareness that Artificial Intelligence (AI) will further affect the financial services sector. Artificial Intelligence's impact on the financial services is essential across two main areas, which are the interactional and conversational layer between the consumer and the firm as well as from internally; and dealing with processes that require humans essentially an activity that can replace humans using algorithms that can learn (King, 2018, p. 223). This evidences that AI affect noteworthy the bank customers experience.

Since the early 2010s, Artificial Intelligence in the banking sector has led to the successful emergence of Neobanks; and recently, Neobanks are acting more and more like traditional banks (Минарченко \& Сайко, 2018, p. 1). Glushchenko et al. (2019) noted that there are almost 70 Neobanks worldwide, with the UK having around 40 Neobanks registered as start-ups. Generally, Neobanks are categorised into two types: one that offers a complete suite of banking services and the other are banks - client applications, which are mainly in America.

Neobanks operate as $100 \%$ digital-only banks, built on new technology and not on outdated infrastructure, which the legacy banks are running on (Likuev and Bermisheva, 2017). Neobanks can easily create a good customer experience because they are not build on the outdated financial infrastructure, allowing Neobanks to operate efficiently. Despite Neobanks success in gaining good customer experience, they do fall short on cross-selling and lending, which remains the most profitable areas within banking (Menon, 2018).

A key distinguishing feature of Neobanks from traditional banks is the easy, relaxed and appealing mobile involvement. Dissimilar to phone banking used by traditional banks (Минарченко \& Сайко, 2018, p.1), Neobanks build on AI elements to uphold normal service offers and offer an additional urbane computer-generated customer associate involvement with Chatbots, enhancing a simple and engaging mobile experience (Gudova, 2018). Furthermore, Menon (2018) outlines the huge value that $\mathrm{AI}$ has on banking and its customer engagement by reiterating that $\mathrm{AI}$ enhances the capability to handle over 1.5-2 million customer queries daily via a virtual agent, as well as increased speed and quality of insights to target and personalise (Menon, 2018, p.12).

In conclusion, the review found that digital banking industry has become more popular to control and manage customer experience by allowing personalisation and interactivity (Salvatore et al., 2016). Finally, the review observed how Artificial Intelligence-powered technology affected the banking industry, including the emergence of Neobanks and its growing popularity with consumers. Menon (2018) observed that artificial intelligence capabilities allow Neobanks to provide high customer engagement levels through virtual agents.

Despite the fact that this review of literature has provided balanced views and conclusions, mainly under the themes of the influence of digital banking on its consumers and the innovative technological impact in the banking industry, further affecting the consumers' experience, research gaps still exist, which necessitate additional examination. These include further research on the impact of virtual 
agents, i.e., Chatbots affecting customers' experience and the importance of Neobanks regarding the extent to which consumers use it as a mode of personal wealth management; and researching more into what age groups utilise certain features of Neobanks.

\subsection{RESEARCH METHODOLOGY}

The study was designed to capture customer perception in England, focussing on whether the digital banking services, such as banking apps provided by traditional banks, actually lead to good customer experiences; and assessing consumers' attitudes towards Neobanks, and whether they can maintain the excellent customer service experience that is claimed by online-only banks implementing virtual agents and algorithms. A survey approach was adopted to ensure that most appropriate data was collected.

\subsection{Primary Study Strategy}

For this study, it was best suited to conduct a descriptive study as it describes the state of affairs as it exists at present (Kothari, 2004). Online surveys allow for using a qualitative approach, which allows the inference of characteristics or relationships of the population (Kothari, 2004). The use of an online survey allowed collecting qualitative data, which was most fitting as the concept of Artificial Intelligence and Neobanks, are contemporary notions not been commonly studied, especially on the experience consumers have faced in the banking sector.

The main benefit of using a survey is that it allows the study to have a more extensive reach to the target population than what interviews would (Jones, et al., 2008) therefore enabling more generalisable conclusions. The use of a survey is beneficial and insightful when learning about a general trend in people's opinions, experiences and behaviour from many people (Driscoll, 2011), which is precisely the aim of this study. The online survey allows more control over the survey during every point of the data collection process (Solomon, 2000). It allows the survey to be visually attractive when designed (Denscombe, 2003), which in turn helps to increase the response rate.

Although, conducting this study through an online-based survey provided some benefits, as mentioned. However, it does contain some constraints and limitations that can affect the study as a whole, and these had to be considered when planning and distributing the survey.

A couple of the main constraints of using an online-based survey included the fact that online surveys are notorious for receiving low response rates and including a certain extent of allied prejudice (Gillham, 2008; and Jones et al., 2008). Another constraint for using an online survey to collect data is the lack of contact among the investigator and those who participate in the survey, which may adversely affect the response rate (Cormack, 2000). Denscombe (2003) highlighted another disadvantage of sampling the research, suggesting that conducting online-based surveys does not represent the research population. This is due to the automatic exclusion of people who may not have access to a phone or computer or those not computer literate (Jones, et al., 2008). Another limitation relevant for this particular study is that the collected data are descriptive, which might affect the research (as suggested by Shah et al., 2015, El-Gohary, et al., 2012; and El-Gohary, 2011).

\subsection{Data Collection}

An electronic questionnaire was used to collect research data to broaden its reach and ease of complete. Data was collected using the SoGoSurvey website. The online survey allowed access directly to the population sample by distributing the link of the survey via email and on social media platforms. The survey was designed to ascertain the participants' responses. The survey consisted of fifteen questions. One of the question was designed to gauge the age demographics of the population that were responding and participating. The remainder of the questions were organised and explicitly focused on the themes relating to the three different study aims. The majority of the survey included closed-ended questions to avoid ambiguity and form a consensus from the survey results (Saunders and Lewis, 2015). However, some questions gave contributors the chance to express their own views. 
Before distributing the survey, the correct population was recognised to ensure that the survey will reach a fair demographic. Therefore, the questionnaire was directed to those predominately living in London, and over 16 years old. The sample was then chosen at random from the population to ensure that there is little or no bias in the results. The sample aimed to reach around 100 to 150 respondents over four weeks. To ensure the response rate was maximised, the survey was posted on social media platforms to widen people's range. Additionally, participants were encouraged to share with others in different fields after completion.

\subsection{Data Analysis}

Data were categorised under the three main themes of the study objectives. The analysis's of the qualitative data collected aimed to provide an initial description and test pre-determined assumptions and produce generalisable results (Marshall, 1996) to carry out a thematic analysis. The results of the data analysis are discussed in the following part of the manuscript.

\subsection{RESULTS AND DISCUSSION}

The research had a total sample size of 150 , of which there were 97 responses, yielding a $64.7 \%$ response rate. Goodrich (1978) observed that a response rate of $50 \%$ should be the minimum to have reliable results. Therefore, the collected data, the responses and conclusions gathered will be worthwhile towards the study and its objectives.

\subsection{Digital Banking and Customers' Experience}

Seven items on the questionnaire aimed to meet the first target of the study, which were dedicated to explore the use of digital banking and the experience that customers face with it. The questions focused on investigating consumers' opinions and attitudes towards the digital services provided to them by their current banks, specifically, their banking apps and websites.

Participants were asked to specify to what extent they conducted their banking needs via an app or not. The results presented below in Figure 1 found that $85.6 \%$ of the sample definitely do, whilst only $2.1 \%$ do not and the rest of the sample only use their banking app sometimes. The survey then continued to find that only $2 \%$ do not use the app, whilst $52 \%$ of the sample used the app because it is easily accessible, and $46 \%$ used the app because it is quick to complete their banking needs. In comparison, $97 \%$ of the respondents had a positive experience with their banking apps. This is reechoed in the results, as 57\% used their banking app at least three times per week, and $25 \%$ use the app once per week.

The results further showed in Figure 2 reveals that customers visited their bank branches few times per year or only once a year or less across all age groups. Interestingly, however, the results found that only $55.7 \%$ think that their banking app or website provides the same services as their bank branch.

Although apps are being chosen over visiting physical bank branches, Figure 5 shows that when consumers face an issue regarding their bank account, their preferred mode of communication is speaking to a bank's representative over the telephone. However, using a banking app or a Chatbot on the banks' website is one of the least favoured options. This result is in line with Arslanian and Fischer (2019) conclusions, which highlighted that consumer' expectations have shifted, meaning that digital services are now expected to be on-demand.

This is reflected in the data collected. A significant number of respondents (52\%) use their banking app due to how easily accessible it is; and $46 \%$ because they can quickly complete their banking needs. In addition to this, the data shows that $57 \%$ of the respondents use their banking app three times per week, and $25 \%$ use it once per week, therefore meaning that the app is available to consumers as and when they desire, hence, on-demand. However, the data collected somewhat discredits one of Arslanian and Fischer (2019) conclusions that banks have been led to implementing technology as young customers were unsatisfied with traditional banking. This would then suggest that young 
Figure 1. Percentage of customers conducting their banking via an app according to their age

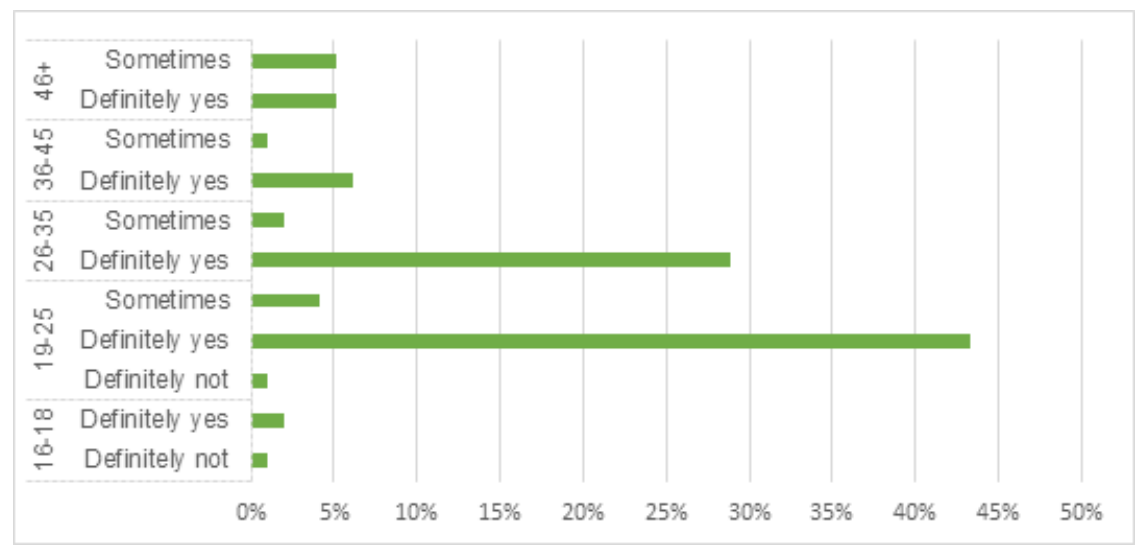

customers predominately use the digital services provided by banks. However, the data in Figure 3 reveals that customers use the app more across all ages, not just young consumers as assumed.

As shown in Figure 4, the respondents visited their local bank branch few times per year or just once a year or less across all ages. This supports the hypothesis made by Lipton et al. (2016), suggesting that digital banking needs to be a holistic and customisable experience, meaning if traditional brick and mortar banks cannot innovate and digitally transform, customer satisfaction will decrease. Therefore, this data helps to prove that digital banking has become a customisable experience so much so that it has become the preferred mode for customers to complete their banking needs rather than visiting their local branches.

\subsection{Artificially Intelligent Technology in Banking}

The next set of questions in the survey focused on exploring the second objective of this study, which was concerned with the artificial intelligence element within the banking industry, specifically AIpowered virtual assistants, otherwise known as Chatbots.

Twenty-six (26) respondents making 13\%, chose Chatbots as their preferred mode of communication with their bank (see Figure 3). The respondents were further asked as to their reason behind this, with the additional option of providing their reason under "other (please specify)". Table 1 presents their responses.

Figure 2. How often customers visit physical bank branches

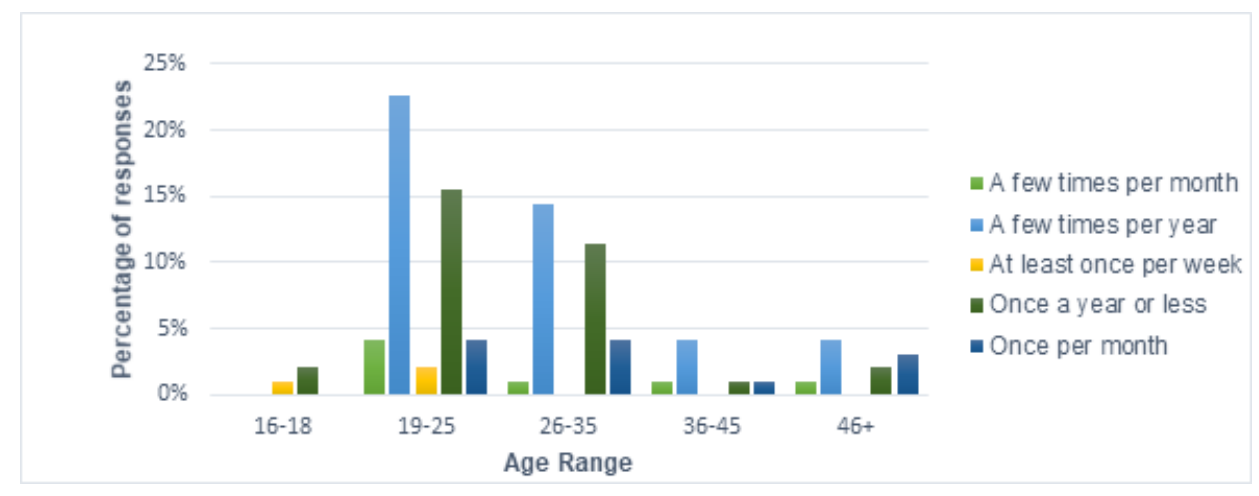




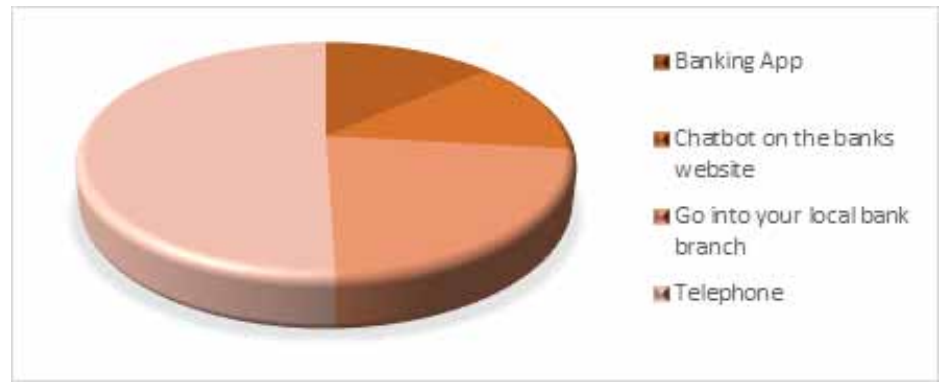

In linking these findings to the literature, the data from Figure 5 and Table 1 found an association with Salvatore et al. (2016), concluding that augmented reality enables the consumer to connect with product experts in real-time. Additionally, King (2018) asserted that AI's development would enhance humans' learning and replacement.

The data in Figure 5, albeit only 13\%, chose that their preferred mode of communication is the Chatbot on the bank's website over speaking to an actual banks representative on the telephone, which was the more popular choice. Looking further into this in Table 1, most of the respondents chose to interact with a Chatbot because it is easier and quicker to use than a human on the phone is. As observed by Salvatore et al. (2016), virtual assistants allow efficient interactivity in real-time. Additionally, the findings suggests that King (2018) assertion can eventually become true in the future as the data from this study points to this direction.

\subsection{Scope of Neobanks and Consumers' Reactions}

The remainder of the survey focused on understanding the scope of Neobanks within the banking industry and how to explore customers' reactions toward the challenger banks.

The first set of questions aimed to gather an idea of what existing awareness banking customers have of Neobanks, resulting in $78 \%$ of the respondents who had heard about online-only banks. Figure 4 illustrates the breakdown of to what extent do the respondents use or do not use an onlineonly bank. Closer inspection of the collected data shows that overall, $57 \%$ of the sample do not hold an online-only bank account, and $86 \%$ do not rely on all their banking needs solely on Neobanks. Interestingly, 54\% of the respondents said they would consider having all their bank accounts with Neobanks in the future; however, $46 \%$ responded they would not.

The mentioned $46 \%$ of respondents from above were further asked to explain their decision. The overriding theme was that there is an element of risk with storing their money in an online-only bank compared to a traditional bank. Additionally, they believe a Neobank does not provide the same services as a traditional bank would, so they prefer having the option to see a staff member. Lastly, the consensus was that the consumers do not currently have enough information about online-only banks to make such a decision.

Table 1. Reasoning behind opting for Chatbots as preferred mode of communication when facing an issue

\begin{tabular}{lr} 
Row Labels & $\overline{\text { Count of Respondents }}$ \\
\hline Equally as trustworthy as talking to a bank representative over the phone & 9 \\
Other (Please specify):I get to take screen shot of conversation to refer back & 1 \\
Quicker and easier to use compared to talking to a bank representative over the phone & 16 \\
\hline Grand Total & 26
\end{tabular}


Figure 4. Data showing if customers do or do not use neobanks according to their age

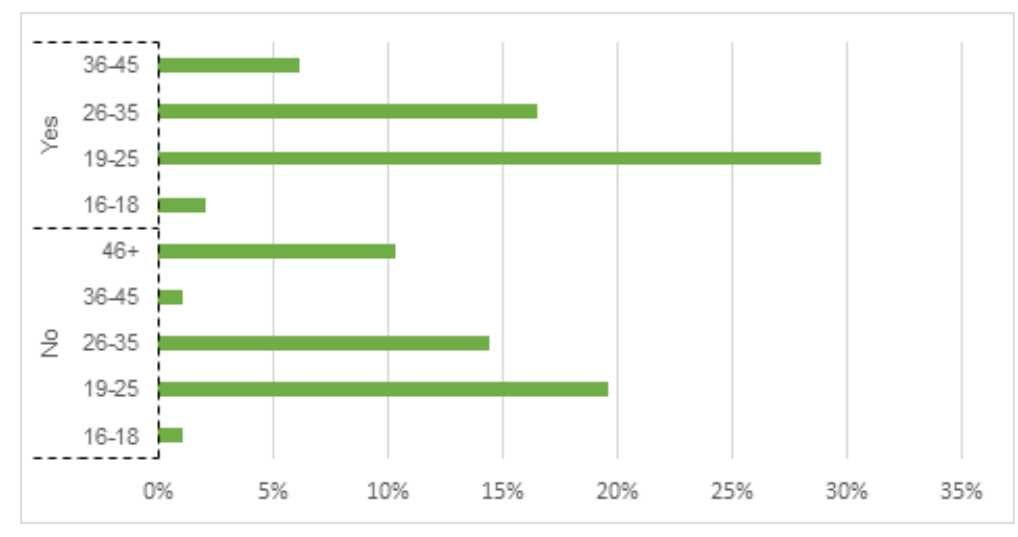

Минарченко (2018) findings was supported to a certain extent from the data collected from this study, concerning consumers' opinions with Neobanks. It proposed that Neobanks are perhaps ideal for only young people with straightforward banking needs. As can be seen from Figure 5, 19-25-yearolds reported holding an online-only bank account, this was significantly more in comparison to the other ages, thus supporting Минарченко's suggestion.

Interestingly, as mentioned, some respondents would not hold an online-only bank account due to believing that a Neobank does not provide the same services as a traditional bank does. This further links with Минарченко (2018) study regarding the conclusion that only those with specific banking needs would hold an account with Neobanks.

\subsection{CONCLUSION}

This research examined how Artificially Intelligent powered technology in the banking sector has affected consumers' experiences. Overall, this study had three objectives to achieve. Considering the key findings, it became evident that:

Figure 5. Data showing why consumers hold an account with a neobank

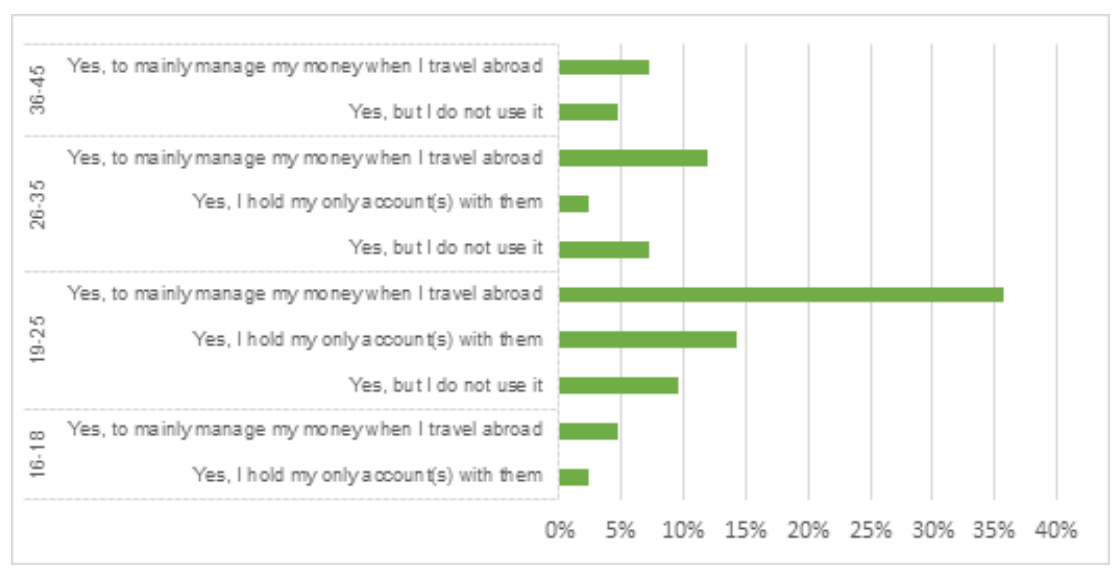


- Consumers are digitally transformed.

- Artificial Intelligence powered technology is not widely accepted.

- Knowledge and information gaps exist regarding Neobanks.

This study's first key finding cut across all demographics, with everyone going through a digital transformation journey. This has led to consumers having the equivalent expectations that their banks should be digitally transforming or already transformed. These expectations have led to banks continuously developing their apps to provide such a positive experience, almost leading to substituting consumers' local bank branch visits. Consumers now use their banking app as their first and initial way to conduct their banking needs.

Secondly, it became evident that Artificial Intelligence powered technology in banks has not had the desired effect on consumers' experience as expected from other studies due to the lack of use of technologies such as Chatbots on banks' apps and websites. This study suggests that using Chatbots could be on the verge of becoming famous and perhaps more trustworthy. The younger generation is using Artificially Intelligent powered technology more due to the ease and convenience provided by Chatbots. Finally, a significant finding to emerge from this study is that consumers lack knowledge of the information available regarding the scope and capabilities of Neobanks. The majority of consumers who hold an online-only bank account only hold it to manage their finances when travelling abroad. Some customers hold an account but do not use it, despite a Neobank having the same capabilities as a traditional bank does. This limited knowledge that consumers have on holding online-only bank accounts has increased the risk of storing money with a Neobank.

\subsection{Limitations}

The generalisability of these results is subject to certain limitations. For instance, the sample size is considered to be small. The survey was handed out to 150 people but only received 97 responses, which meant that generalising the responses from the data as the voice for all banking customers' population might make the conclusions not as reliable as the research team wished for.

An additional uncontrolled factor of the study was the demography that responded to the survey. Almost half of the respondents were predominately between the ages of 19 and 25, which meant that the survey results did not show a fair distribution across all ages, meaning that there is a potential bias for 19 to 25 -year-olds in the results.

Furthermore, the study was limited to an extent as the survey only collected data in a short window period. For the most part, from those who only live in London, generalising the data is not as reliable.

The study could be made more prominent in future, thereby enhancing generalisability. Additionally, interviews from neobanks would enhance the study and perhaps provide more in-depth conclusions to the objectives.

\subsection{Recommendation of the Research}

It would be interesting for an investigation to be conducted on what consumers are expecting in the future of digital banking, such as what consumers want from their banking app(s) more than what the app provides currently, which could potentially lead to the complete substitution of visiting local bank branches, whilst increasing a positive customer experience.

Whilst conducting this study through an online-based survey, it became apparent that not many consumers use the Chatbot services provided through their banking app and website. The main consensus was that there were potential trust and reliability issues that consumers had with them. Therefore, they opted to mainly contacting their bank through the telephone. Although previous studies showed that Artificial Intelligence powered technology, such as virtual agents, i.e. Chatbots, provide the same information as a banks' representative would due to AI's hyper-intelligence capability, thus providing guaranteed positive customer service; however, as observed from this study, consumers rarely opt to use a virtual agents. Therefore, investigating more into why consumers do not choose 
Chatbots as their preferred mode of communication could then help in solving the issues that banks currently face of their customers not using the Chatbots on their banking app and website as much as they would prefer to ensure a positive consumer experience, especially when consumers face banking issues or problems.

The final recommendation is to ensure that consumers have enough knowledge and information about neobanks and holding bank accounts with them. Throughout the data collection process of this study, it became evident that consumers had substantial knowledge gaps on neobanks, their capabilities and facilities that online-only banks hold, which is beyond managing money whilst travelling abroad, which is what a small percentage of the consumers currently think. Therefore, it would be appropriate to investigate what sort of demographics do not hold an online-only bank account. Alongside this, a study could further explore whether consumers do not hold an account with neobanks due to the lack of information available from neobanks to the consumers directly or investigating if neobanks are not reaching their potential consumers. This might be due to the lack of advertising of their benefits and the services they can provide to fulfil consumers' necessary banking needs whilst ensuring a substantial positive customer experience.

\subsection{Implication of the Research}

The study implies that digital banking is very much at the forefront of helping consumers with their banking needs and even facing banking issues. This implies that banks can further develop their banking apps and aim to provide more services to its customers through their banking app(s) to ensure that they reach all the demands that consumers want through their banking apps to ultimately improve banking clients' involvement. Moreover, consumers perhaps misunderstand the capabilities of virtual agents in banks; thus, there is a need for banks to identify the benefits of using a virtual agent such as a Chatbot to its consumers, emphasising that Chatbots are reliable and trustworthy. Finally, neobanks may want to investigate further in-depth as to why the majority of the population do not hold as many online-only bank accounts as expected and see if more information needs to be relayed across to its existing customers, explaining the benefits and different uses of holding an account with a neobank. 


\section{REFERENCES}

Минарченко, И., \& Сайко, И. (2018). The Future Of Neobanks. In The Development Of Banking Sector. Polessky State University.

Ameen, N., Tarhini, A., Reppel, A., \& Anand, A. (2021). Customer experiences in the age of artificial intelligence. Computers in Human Behavior, 114, 106548. doi:10.1016/j.chb.2020.106548 PMID:32905175

Arslanian, H., \& Fischer, F. (2019). The Rise of Fintech. The Future of Finance, 25-56. doi:10.1007/978-3030-14533-0_3

Binner, J. M., Kendall, G., \& Chen, S.-h. (2004). Applications of Artificial Intelligence in Finance and Economics. Elsevier Ltd. doi:10.1016/S0731-9053(2004)19

Bradford, T. (2020). Neobanks: Banks by Any Other Name? Payments System Research Briefing.

Brown, S. A. (2000). Customer relationship management: Linking people, process and technology (1st ed.). Wiley.

Buttle, F., \& Maklan, S. (2015). Customer Relationship Management: Concepts and Technologies (3rd ed.). Routledge. doi: $10.4324 / 9781315764597$

Cormack, D. (2000). The Research Process in Nursing (4th ed.). Blackwell Sciences.

Denscombe, M. (2003). The Good Research Guide: for small-scale research projects (2nd ed.). Open University Press.

Driscoll, D. L. (2011). Introduction to Primary Research: Observations, Surveys, and Interviews. Writing Spaces: Readings on Writing, 2, 153-174.

Eid, R., \& El-Gohary, H. (2015a). Muslim Tourist Perceived Value in the Hospitality and Tourism industry. Journal of Travel Research, 54(6), 774-787. doi:10.1177/0047287514532367

Eid, R., \& El-Gohary, H. (2015b). The role of Islamic religiosity on the relationship between perceived value and tourist satisfaction. Tourism Management, 46, 477-488. doi:10.1016/j.tourman.2014.08.003

El-Gohary, H. (2010). E-Marketing: Towards a Conceptualization of a New Marketing Philosophy. In E-Business Issues, Challenges and Opportunities for SMEs: Driving Competitiveness. IGI Global.

El-Gohary, H. (2011). Customer Relationship Management Adoption in Developing Economies: The Case of Egyptian Small Business Enterprises. Proceedings of the ISBE 2011 Conference, Sustainable Futures: Enterprising Landscapes and Communities.

El-Gohary, H., O'Leary, S., \& Radway, P. (2012). Investigating the Impact of Entrepreneurship Online Teaching on Science and Technology Degrees on Students attitudes in Developing Economies: The case of Egypt. International Journal of Online Marketing, 2(1), 29-45. doi:10.4018/ijom.2012010103

Fintech News. (2018). Digital banking and neobanks. Available at: https://www.fintechnews.org/digital-bankingand-neobanks/

Gillham, B. (2008). Developing a questionnaire. A\&C Black.

Glushchenko, M., Hodasevich, N., \& Kaufman, N. (2019). Innovative financial technologies as a factor of competitiveness. SHS Web of Conferences, 69, 43.

Goodrich, W. (1978). Dillman, Don. Mail and Telephone Surveys-the Total Design Method. Journal of Advertising, 8(1), 52-52. doi:10.1080/00913367.1979.10673275

Gudova, M. (2018). Digital banking and neobanks. Fintech News. Available at: https://www. fintechnews. org/ digital-banking-and-neobanks

Hoyer, W. D., Kroschke, M., Schmitt, B., Kraume, K., \& Shankar, V. (2020). Transforming the customer experience through new technologies. Journal of Interactive Marketing, 51, 57-71. doi:10.1016/j.intmar.2020.04.001

Jones, S., Murphy, F., Edwards, M., \& James, J. (2008). Doing things differently: Advantages and disadvantages of web questionnaires. Nurse Researcher, 4(4), 15-26. doi:10.7748/nr2008.07.15.4.15.c6658 PMID:18700656 
Joseph, M., Sekhon, Y., Stone, G., \& Tinson, J. (2005). An exploratory study on the use of banking technology in the UK. International Journal of Bank Marketing, 23(5), 397-413. doi:10.1108/02652320510612474

Kannan, P., \& Bernoff, J. (2019). Harvard Business Review. Available at: https://hbr.org/2019/05/does-yourcompany-really-need-a-chatbot

Kauflin, J. (2019). Dawn Of The Neobank: The Fintechs Trying To Kill The Corner bank. Forbes. Available at: https://www.forbes.com/sites/jeffkauflin/2019/11/04/dawn-of-the-neobank-the-fintechs-trying-to-kill-thecorner-bank/\#3aab690eb0f6

King, B. (2018). Bank 4.0: Banking everywhere, never at a bank. John Wiley \& Sons. doi:10.1002/9781119506515

Klaus, P., \& Maklan, S. (2013). Towards a Better Measure of Customer Experience. International Journal of Market Research, 55(2), 227-246. doi:10.2501/IJMR-2013-021

Klein, L. R. (2003). Creating virtual product experiences: The role of telepresence. Journal of Interactive Marketing, 17(1), 41-55. doi:10.1002/dir.10046

Kline, A. (2015). Five Reasons You Can't Ignore the Neobanks. American Banker, 1(65).

Kothari, C. R. (2004). Research methodology: Methods and techniques. New Age International.

Lemon, K. N., \& Verhoef, P. C. (2016). Understanding customer experience throughout the customer journey. Journal of Marketing, 80(6), 69-96. doi:10.1509/jm.15.0420

Liang, T., Ho, Y., Li, Y., \& Turban, E. (2011). What drives social commerce: The role of social support and relationship quality. International Journal of Electronic Commerce, 16(2), 69-90. doi:10.2753/JEC10864415160204

LikuevA.BermishevaP. (2017). Forbes. Available at: https://www.forbes.ru/tehnologii/344459-neobankibudushchee-ili-tupikovaya-vetv-razvitiya-bankovskoy-sistemy

Lipton, A., Shrier, D., \& Pentland, A. (2016). Digital banking manifesto: the end of banks? Massachusetts Institute of Technology.

Marshall, N. M. (1996). Sampling for qualitative research. Family Practice, 13(6), 522-526. doi:10.1093/ fampra/13.6.522 PMID:9023528

Mbama, C. (2018). Digital banking, customer experience and bank financial. Sheffield: SHURA.

McWaters, J. (2017). World Economic Forum. Available at: http://www3.weforum.org/docs/Beyond_Fintech__A_Pragmatic_Assessment_of_Disruptive_Potential_in_Financial_Services.pdf

Menon, A. D. (2018). Future of Banking. Tallyx.

Moysan, Y., \& Zeitoun, J. (2019). Chatbots as a lever to redefine customer experience in banking. Journal of Digital Banking, 3(3), 242-249.

Nicoletti, B., Nicoletti, W., \& Weis. (2017). Future of FinTech. Basingstoke, UK: Palgrave Macmillan.

Qualtrics. (n.d.). Cross Tabulation for Researchers. Available at: https://www.qualtrics.com/uk/experiencemanagement/research/analysis-reporting/cross-tabulation/

Raghubansie, A., El-Gohary, H., \& Samaradivakara, C. (2015). An Investigation of the Evaluation of the Viral Marketing Research - Book Chapter. In Marketing and Consumer Behavior: Concepts, Methodologies, Tools, and Applications (pp. 201-227). IGI Global. doi:10.4018/978-1-4666-7357-1.ch010

Rajola, F. (2013). Customer Relationship Management in the Financial Industry (2nd ed.). Springer-Verlag. doi:10.1007/978-3-642-35554-7

Remolina, N. (2020). Towards a Data-Driven Financial System: The Impact of Covid-19. SMU Centre for AI \& Data Governance Research Paper, (8).

Salvatore, P., Guinan, P. J., \& Kafka, R. (2016). Solving the crisis of immediacy: How digital technology can transform the customer experience. Business Horizons.

Saunders, M., \& Lewis, P. T. A. (2015). Research Methods for Business Students. Pearson. 
Schueffel, P. (2016). Taming the beast: A scientific definition of fintech. Journal of Innovation Management, 4(4), 32-54. doi:10.24840/2183-0606_004.004_0004

Schwager, A., \& Meyer, C. (2007). Harvward Business Review. Available at: https://hbr.org/2007/02/ understanding-customer-experience

Shah, S., El-Gohary, H., \& Hussain, J. (2015). An investigation of Market Orientation and Tourism SMEs Performance in Developing Countries: A review of the literature. Journal of Travel \& Tourism Marketing, 32(8), 990-1022. doi:10.1080/10548408.2014.957372

Shaikh, A. A., \& Karjaluoto, H. (2015). Mobile banking adoption: A literature review. Telematics and Informatics, 32(1), 129-142. doi:10.1016/j.tele.2014.05.003

Shaw, C., Dibeehi, Q., \& Walden, S. (2010). Customer Experience Future Trends and Insights (1st ed.). Palgrave Macmillan. doi:10.1057/9780230291775

Shaw, C., \& Ivens, J. (2002). Building Great Cusomter Experiences (1st ed.). Palgrave Macmillan. doi: $10.1057 / 9780230554719$

Solomon, D. J. (2000). Conducting web-based surveys. Practical Assessment, Research \& Evaluation, 7(19).

Sundarraj, R. \& Wu, J. (2005). Using information-systems constructs to study online-and telephone-banking technologies. Electronic Commerce Research and Applications, 4, 427-443.

Temelkov, Z. (2020). Differences between traditional bank model and fintech based digital bank and neobanks models. SocioBrains, (74), pp.8-15.

Vives, X. (2017). European Economy. Available at: https://european-economy.eu/2017-2/the-impact-of-fintechon-banking/

Wewege, L. (2017). The Digital Banking Revolution. Lulu.com. 


\section{APPENDIX A. ADDITIONAL DATA COLLECTED FROM SURVEY}

Figure 6. Data showing the count of respondents who use their banks Chatbots according to their age

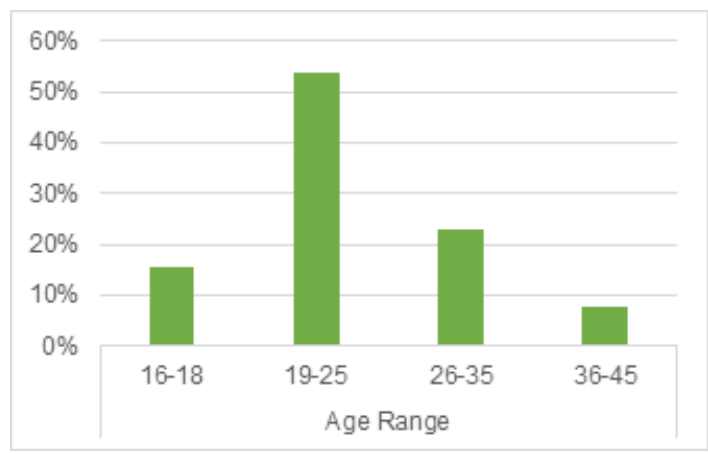

Figure 7. Chart showing why customers use their banking app

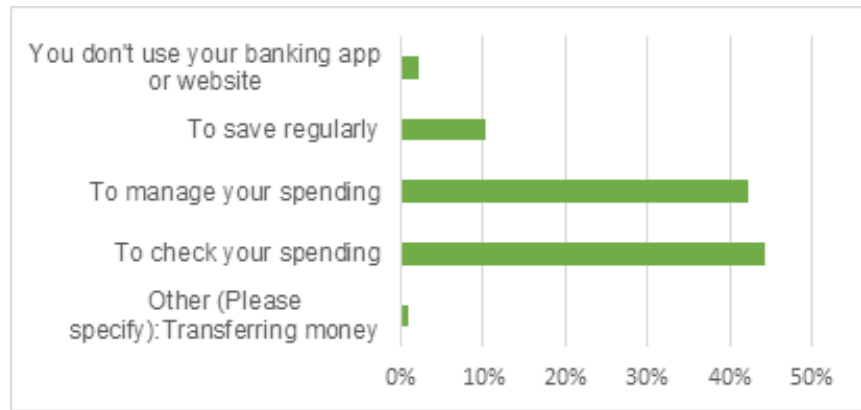

Figure 8. Data showing if respondents reply to all their banking needs with neobanks

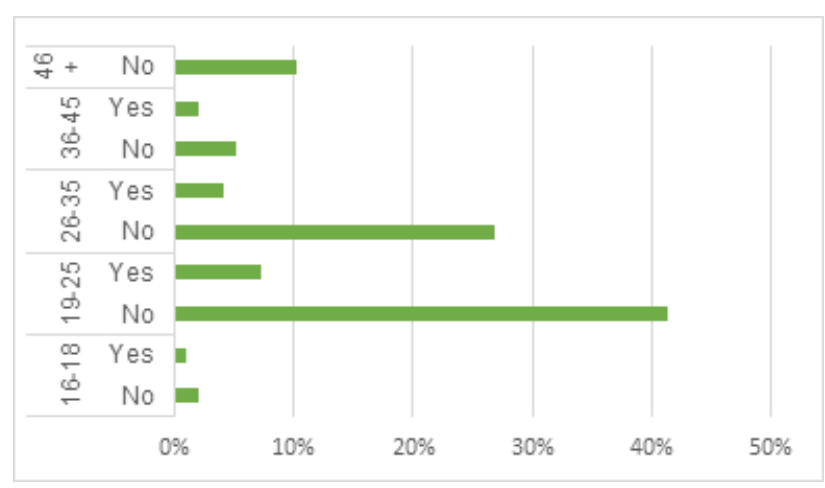


Figure 9. Data showing how many respondents would and would not hold their accounts with neobanks in the future

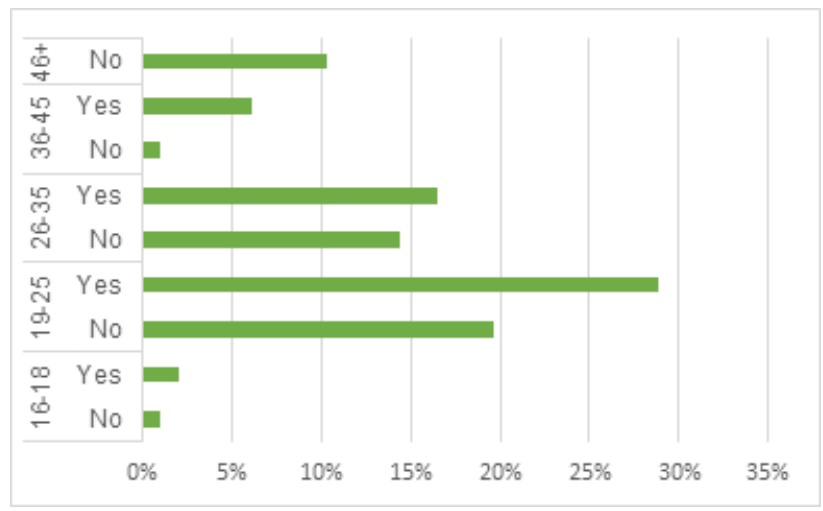

Figure 10. Count of respondents who use Chatbots as their preferred mode of communication according to age group.

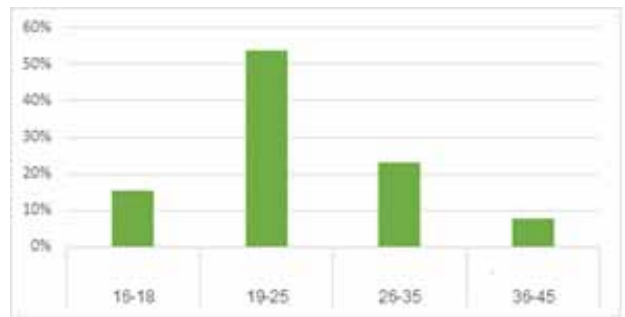


Hatem El-Gohary (Professor) is the Editor-in-Chief of the IJOM, Associate Editor of IJCRMM and the UK Director for the Institute for Research on Global Business (UK). He has more than 28 years of experience in academia, worked as the marketing director of a multinational company as well as a marketing consultant for some national and multinational companies. His research interest includes Electronic Marketing, Electronic Business, Electronic Commerce, Internet Marketing and SMEs. He has published several books, articles and book chapters and presented several research papers in various world-leading well-established international conferences. He holds a PhD, MSc, MRes, PGDip, BSc as well as PGCHE. He is also a Certified E-Marketer (CeM), an AABPP Fellow, HEA Fellow, CMI Fellow, CIM member (MCIM) and has a significant record of experience in voluntary work in Egypt and the UK. Prof El-Gohary won The ISBE2014 Best Paper Award (Creative Industries Entrepreneurship Track), The American Academy of Business and Public Policy Best Paper Award 2009, Routledge Best Paper Award 2007 and the Ideal Student for Cairo University Award 1992.

Aksaya Thayaseelan is a researcher at Birmingham City University Business School, Birmingham, UK. She is interested in the fields of technology, education, entrepreneurship, SMEs, and business.

Simeon Babatunde $(P h D)$ is an active researcher at Birmingham City University Business School. He published a number of research papers in the fields of education, entrepreneurship, SMEs, and business. He also presented a good number of papers at international well-established conferences.

Salma El-Gohary is a marketing researcher at Qatar University that has a great interest in marketing, eCommerce, eBusiness, and small businesses. She published a number of papers and book chapters in these fields. 